\title{
Práticas de si no discurso de professores do ensino superior: diálogos entre Foucault e Hadot ${ }^{1}$
}

\author{
Luciana Aparecida Silva de Azeredo ${ }^{2}$ \\ Márcia Aparecida Amador Mascia ${ }^{3}$
}

\section{Resumo}

Este artigo objetiva empreender uma análise discursiva de dizeres de professores do ensino superior sobre o cuidado (de si), à luz de Foucault, autores pós-foucaultianos e Hadot. Seu intuito é apontar como os efeitos de sentido de cuidado (de si) estão atrelados aos modos de subjetivação/objetivação, às técnicas neoliberais de governamentalidade e rastrear possíveis presenças dos modos de subjetivação, o cuidado de si nas falas. Constatouse o quão enredados estão os entrevistados nas/pelas técnicas neoliberais de governamentalidade e a importância de manter acesa a esperança na possibilidade de fazer de nossas vidas um ensaio de nós mesmos, em constante transformação, apostando na relação consigo como uma alternativa, uma forma de resistência diante do poder (pós)moderno.

Palavras-chave: Cuidado de si; Modos de subjetivação/objetivação; Governamentalidade; Docência.

\section{Practices of the self in the discourse of higher education professors: dialogues between Foucault and Hadot}

\begin{abstract}
This paper aims to undertake a discursive analysis of the words of teachers of higher education on the care (of the self), in the light of Foucault, post-Foucauldian authors and Hadot. Its purpose is to point out how the effects of meaning of the care (of the self) are linked to the modes of subjectivation/objectivation, to the neoliberal techniques of governmentality and to trace the possible presence of modes of subjectivation, care of the self in their speech. It was observed how tangled the interviewees are in the neoliberal techniques of governmentality and the importance of keeping alive the hope of making our lives a draft of ourselves, in constant transformation, believing in the relationship with oneself as an alternative, a form of resistance to (post)modern power.

Keywords: Care of self; Modes of subjectivation / objectivation; Governmentality; Teaching.
\end{abstract}

\section{Considerações iniciais}

Atualmente, temos vivido "em um mundo incerto, complexo e plural, um mundo inseguro e cheio de contradições, paradoxos, injustiças, problemas e necessidades de todos os tipos" (MORAES; NAVAS, 2010, p.8), problemas estes movidos, em especial, pela Globalização, Capitalismo, Neoliberalismo, que nos impelem, incessantemente, à produtividade, à competitividade, ao narcisismo e ao exibicionismo exacerbado. Há, como apontam alguns

\footnotetext{
${ }^{1}$ O presente trabalho foi realizado como apoio da Coordenação de Aperfeiçoamento de Pessoal de Nível Superior Brasil (CAPES) - Código de Financiamento 001.

${ }^{2}$ Centro Federal de Educação Tecnológica de Minas Gerais, Belo Horizonte, luciana.azeredo@cefetmg.br

${ }^{3}$ Universidade São Francisco, Itatiba, marcia.mascia@usf.edu.br
} 
autores, uma crise existencial, que faz com que as pessoas apenas sobrevivam ou vegetem em um grande vazio existencial que as impede de encontrar um sentido em suas vidas e em seus caminhos de autorrealização, além de viverem afetadas por uma psicopatologia invisível, que $P$. Weil e J.Y. Leloup denominaram "normose", como ressaltam Moraes e Navas (2010), e que inclui, entre outros aspectos, condutas ansiosas, intolerantes, agressivas, ególatras, violentas, esquizoides e depressivas, por muitos considerados como sendo normais (MORAES; NAVAS, 2010, p. 8).

Tais condutas alimentam e são alimentadas pelo paradigma neoliberalista, dentro do qual nos situamos e estão situados os sujeitos desta pesquisa. O Neoliberalismo é uma forma de generalização da visão empresarial a todas as outras formas de conduta, inclusive as relacionadas ao contexto educacional, ou seja, a promoção da cultura de empresa, transformando os indivíduos em "empresários de si mesmos". Esta "noção de cultura de empresa tem sido construída no sentido econômico mais estreito. Ela é parte de uma nova metanarrativa que, em termos retóricos, nos apresenta uma visão de futuro baseada na expectativa de crescimento econômico" (PETERS, 2011, p. 223). Esta cultura envolve "remodelar as instituições de acordo com critérios comerciais e encorajar a aquisição e uso de qualidades empresariais e empreendedoras" (PETERS, 2011, p. 222).

Nesta perspectiva, critica-se tanto o estado de bem-estar social e também outros sistemas como o educacional por promoverem uma "cultura de dependência". O mundo escolar e acadêmico, como veremos na seção seguinte, não escapa à "cultura da auditoria" (SPARKES, 2007), que exige cada vez mais dos professores/pesquisadores, fazendo com que estes, para (sobre/con)viver nesse mundo dos números, estatísticas e quantidades, tenham que assumir características comumentemente esperadas de homens de negócios, como habilidades organizacionais, estratégias de autopromoção e de networking, entre outras, o que tem intensificado o mal-estar vivenciado na sociedade e levado muitos professores a adoecerem, física ou psicologicamente, como veremos mais adiante.

Isso posto, o objetivo deste artigo, recorte da tese de doutorado intitulada "O docente do ensino superior e o cuidado (de si): entre os modos de objetivação e subjetivação na contemporaneidade", de 2018, é empreender uma análise discursiva de dizeres de professores

Periódico Horizontes - USF - Itatiba, SP - Brasil - e019028 
do ensino superior sobre as práticas de cuidado de si, à luz da interface do pensamento de Foucault, autores pós-foucaultianos e Hadot, sendo este uma das fontes teóricas da terceira fase foucaultiana. O intuito da análise é apontar em que medida os efeitos de sentido de cuidado (de si) estão atrelados aos modos de subjetivação/objetivação, no sentido das técnicas neoliberais de governamentalidade e também rastrear possíveis presenças dos modos de subjetivação, entendidos como cuidado de si filosófico foucaultiano nas falas dos sujeitos-professoresparticipantes.

O presente artigo divide-se em três seções. A primeira apresentará o contexto de pesquisa, a segunda o conceito de cuidado de si, com base em Foucault $(2010 ; 2013)$ e Hadot (2014) e, na terceira, serão analisados excertos de entrevistas semiestruturadas realizadas com professores de ensino superior. $\mathrm{O}$ artigo conta ainda com um ensaio final.

\section{Contexto de pesquisa}

No mundo neoliberalista que nos constitui e é por nós constituído, "os pobres de hoje são, antes e acima de tudo, consumidores falhos, incapazes de tirar vantagem dos tesouros tantalizantemente exibidos a seu alcance, frustrados antes do ato, inabilitados mesmo antes de experimentar" (BAUMAN, 1998, p. 227). Ademais, o receio de ser um consumidor falho e/ou o desejo de ser um consumidor ideal pode levar, a nosso ver, muitos professores a trabalharem em duas ou três instituições, com aulas nos três períodos, uma vez que só desta forma, beirando o esgotamento físico e mental, conseguem estar na roda do mercado. Neste contexto "empresarial" generalizado, não há tempo a perder, pois "time is money" e a solução ou resposta para as dores e angústias deve ser rápida para que o sujeito possa prontamente voltar a sua atuação. Desse modo, "o sujeito se esvai progressivamente da possibilidade de dominar livremente seu tempo, engolido que é pelas montagens quantificantes do social" (BIRMAN, 1999, p. 267). Posto de outro modo, seu tempo deve ser gasto com formas de exibir-se aos outros por meio de carros, casas, viagens e outros bens, ainda que para isso tenha que trabalhar 12 horas por dia, sem, na maioria das vezes, ter tempo para o SER, para o ESTAR com seus entes queridos, seus animais de estimação e seu jardim, para fazer algo por/para si, sem importar-se com os

Periódico Horizontes - USF - Itatiba, SP - Brasil - e019028 
demais, suas opiniões, ou e também se isso Ihe trará ou não benefícios financeiros. Enfim, há tempo apenas para sobreviver e não para (con)viver.

A este respeito, Birman afirma que a modernização do social provocou muitas mudanças na constituição da subjetividade, obrigando-a a se remodelar constantemente "em consequência dos processos de transformação contínua da ordem social, que se realizam de maneira intensiva e extensiva" (BIRMAN, 1999, p. 79). O mapa perdeu/perde seu valor de fornecer rotas precisas, seguras e certas, que nos levem ao destino esperado de forma suave. 0 mundo tradicional de outrora é/foi

[...] desmapeado, perdendo seu traçado de linhas claras e precisas. A geografia fica borrada pela história, perdendo sua nitidez e a simplicidade de seus desenhos. $O$ mundo adquire uma dimensão de infinitude, já que as rotas e os caminhos se multiplicam numa espécie de espiral ascendente. Incrementa-se muito, dessa maneira, o potencial de incerteza do sujeito. A insegurança e a angústia se multiplicam, como consequência. Estas se transformam em sua qualidade, assumindo novas formas anteriormente inexistentes, além de seu aumento quantitativo. Em função disso, o desamparo do sujeito se incrementa bastante, revelando-se o tempo todo como uma ferida exposta e sangrenta. Enfim, o sujeito passa a se inscrever num mundo que the abre muitas possibilidades, mas que também lhe aponta muitas impossibilidades existenciais (BIRMAN, 1999, p. 79).

Hoje, em substituição aos mapas precisos, são necessários os GPS (Sistema de Posicionamento Global, Global Positioning System, em inglês), que recalculam a rota a cada erro de quem guia. Fazendo um paralelo com a teoria darwinista, atualmente, aquele que mais se adapta e adequa às mudanças constantes de/no trajeto, aos terrenos inesperados e inóspitos da contemporaneidade ou, em termos birmanianos,

aqueles que conseguem fazer uma boa gestão do seu mal-estar e do desamparo constitutivos, conseguirão (con/sobre)viver, sem lançar mão dos psicofármacos e das drogas pesadas que apenas amenizam ou escondem as incertezas e inseguranças com as quais temos que conviver nos dias atuais, sem esconderse por detrás das religiões e/o quaisquer terapias alternativas ${ }^{4}$, que hoje abundam, na busca incessante e incansável por soluções rápidas e indolores.

4 Dentre elas, acupuntura, aromaterapia, ioga, watsu, geoterapia, quiropraxia, shiatsu, reiki etc. Fonte: https://claudia.abril.com.br/saude/11-tipos-de-terapias-alternativas-para-aliviar-a-dor-e-o-estresse/. Acesso em: 14 jan. 2018.

Periódico Horizontes - USF - Itatiba, SP - Brasil - e019028 
Talvez a aprendizagem e a aplicação de práticas de si/exercícios espirituais, dos quais trataremos mais adiante, possam não resolver as questões, dissipar as incertezas ou aportar soluções, mas pode auxiliar-nos a fazer uma melhor gestão do desamparo e do mal-estar inerentes à vida humana. Em outras palavras, funcionar como um GPS (AZEREDO, 2018, p. 60-61)

Diante deste panorama de mal-estar e desamparo, apontado não só por Birman (1999), por Freud (1929/2011), há quase um século, retomado por Bauman (1998) e outros autores, que nos afeta dentro e fora das instituições de ensino, mudanças parecem ser necessárias, mas quais e como, ainda nos perguntamos. Para Moraes e Navas (2010, p.8), elas não consistem apenas em combater o paradigma civilizatório vigente, mas também em ter a compreensão de que "tudo está interligado, religado e que, querendo ou não, somos seres limitados chamados a transcender e a participar de diferentes níveis de realidade e que vão muito mais além do estritamente material, sensorial ou psicológico". Dito de outro modo, na perspectiva foucaultiana, faz-se necessário, "jamais parar de pensar. É perguntar, sempre e uma vez mais: por que tem de ser assim? Por que não poderia ser de outra maneira? Por que devemos acreditar no que nos dizem, agora, se, antes, já nos disseram tantas coisas, tantas vezes, tão diferentes?", como aponta Costa $(1999, \text { p. } 20)^{5}$.

Além disso, ressaltamos que o foco principal deste trabalho é versar sobre o cuidado de si filosófico foucaultiano, o que nem sempre implica calmaria, mas sim desassossego ao lidar com nossas faltas e equívocos que a sociedade contemporânea neoliberal procura tamponar por meio da banalização do cuidado, a serviço da ideologia neoliberal. Tal ideologia não aceita sofrimento, tristeza, fracasso, impõe o discurso da felicidade, o que pode intensificar o sentimento de mal-estar da/na docência.

\section{Fundamentação teórica}

Há várias acepções de cuidado (de si) ${ }^{6}$, mas, a adotada nesta pesquisa tem como

\footnotetext{
${ }^{5}$ No prefácio do livro “Amizade e Estética da Existência em Foucault” de Francisco Ortega, cujas referências constam neste trabalho.

${ }^{6} \mathrm{Na}$ referida tese, foi usado "cuidado (de si)" para referir-nos tanto ao cuidado como tido pelo senso comum quanto ao cuidado de si filosófico foucaultiano, uma vez que os entendemos como diferentes, mas imbricados, sendo, por

Periódico Horizontes - USF - Itatiba, SP - Brasil - e019028
} 
embasamento teórico o cuidado de si, tema dos livros da "terceira fase" foucaultiana, a da Hermenêutica do Sujeito, que inclui um volume intitulado "o cuidado de si", e também foi abordado nas aulas do Collège de France e em seminários, como o realizado na Universidade de Vermont em 1982, intitulado As Tecnologias de Si. O termo cuidado de si foi consagrado por Sócrates e retomado pela filosofia posterior, esta concebida como uma arte da existência. Conforme Castro, em seu vocabulário de Michel Foucault ${ }^{7}$ (2004), este filósofo estudou a história da subjetividade, não pelas dicotomias, por exemplo, louco-não louco, mas pela formação e pelas transformações em nossa cultura das relações consigo mesmo, seu arcabouço técnico e seus efeitos de saber, ou visto por outro ângulo, a governamentalidade, o governo de si por si em sua articulação com os outros.

A epiméleia heautoû (cuidado de si), relacionada com o preceito délfico gnôthi seautón (conhece-te a ti mesmo) é, de acordo com Foucault (2010, p.6), "uma espécie de aplicação concreta, precisa e particular, da regra geral, é preciso que te ocupes contigo mesmo, que não te esqueças de ti mesmo, que tenhas cuidado contigo mesmo". Segundo Foucault (2010; 2013), é preciso que o cuidado de si seja definido de tal maneira que dele possa derivar o saber necessário não só para governar os outros, mas para modificar-se, transformando-se em um ser singular, cuja vida é uma obra de arte. "Deve-se ser, para si mesmo e ao longo de toda sua existência, seu próprio objeto" (Foucault, 1997, p.123). Sêneca, Plutarco e Epiteto recomendam "residir em si mesmo", uma conversão a si (ad se convertere), cujo objetivo é relacionar-se consigo mesmo.

O autor (2010) também nos aponta o que deve ser levado em conta na noção de epiméleia heautoû: 1) é uma atitude para consigo mesmo, para com os outros ao seu redor e para com o mundo no qual se está inserido; 2) é uma conversão do olhar, do exterior, dos outros e do mundo para o interior, para si mesmo. É atenção ao que se pensa e ao que se passa no seu pensamento, o que requer exercício e meditação; 3) designa também ações exercidas de si para consigo, nas quais "nos assumimos, nos modificamos, nos purificamos, nos transformamos e nos transfiguramos" (FOUCAULT, 2010, p.12).

vezes, difícil distingui-los nas respostas concedidas pelos sujeitos-professores-participantes. Vale mencionar que, aqui e em outros pontos desta tese, a opção pelo uso do parêntesis foi baseada na perspectiva desconstrutivista derridiana.

${ }^{7}$ A versão usada foi em espanhol, em PDF, com tradução livre nossa.

Periódico Horizontes - USF - Itatiba, SP - Brasil - e019028 
Quando a aplicação a si se tornou uma prática a ser realizada ao longo de toda a vida, seu papel pedagógico de preparação para a vida adulta foi apagando-se e outras funções surgindo. Dentre elas, destacam-se: 1) crítica: desaprender (de-discere) os maus hábitos e falsas opiniões recebidos dos outros, mestres, familiares etc.; 2) de luta: combater durante toda a vida, luta para o qual se deve equipar o indivíduo com armas e coragem; 3) curativa e terapêutica: curar as doenças (pathos) da alma é papel da filosofia para epicuristas, cínicos e estoicos.

Ademais, precisamos de discursos verdadeiros ou racionais, de logoï ou verídica dicta, como era chamado por Lucrécio. Tais discursos "permitem conjurar nossos temores e não nos deixar abater por aquilo que acreditamos serem infelicidades" (FOUCAULT, 1997, p.127). Para ele, os discursos verdadeiros constituem o equipamento necessário que nos permite afrontar o real. A seu respeito, Foucault menciona três questões primordiais: sobre sua natureza; seu modo de existência e sobre técnicas de apropriação.

A verdade está, em Foucault, atrelada ao cuidado de si, sobretudo quando o autor revisita a noção de parrhesía. Etimologicamente, parrhesía significa dizer tudo (pan rêma) e para Demóstenes (apud FOUCAULT, 2011, p.10), é necessário “falar com parrhesía, sem recuar diante de nada, sem esconder nada". Segundo Ortega (1999, p.104), trata-se de uma noção muito complexa que representa "ao mesmo tempo, virtude, habilidade, obrigação e técnica que deve caracterizar sobretudo o indivíduo, cuja tarefa é a direção de outros indivíduos na sua constituição como sujeitos morais". Ortega (1999) ainda menciona que esta noção difere dos outros modos de dizer a verdade, pois não representa "nem uma estratégia de comprovação, nem de convicção, instrução ou diálogo, embora possua elementos de todas elas" (ORTEGA, 1999, p.107). Conforme o autor, "podemos falar de parrhesía quando as circunstâncias aparecem de tal maneira que o fato de dizer a verdade, ou de tê-la dito, produz ou pode produzir consequências custosas" (ORTEGA, 1999, p.107). Dito de outro modo, o parresiasta "abre um risco indeterminado e dependente da situação" (ORTEGA, 1999. p.107). De acordo com Ortega (1999, p.108), a parrhesía aparece "no contexto da relação entre a obrigação de se ligar à verdade mediante o dizer verdadeiro e o exercício da liberdade". Trata-se de constituir-se mediante o cuidado constante com a verdade, por meio do qual "o sujeito constitui-se de forma autônoma como agente do dizer verdadeiro. Trata-se [, em suma,] de uma técnica de si, de uma 
ascese e de uma prática de liberdade" (ORTEGA, 1999, p.112). Segundo Ortega (1999, p.113), Foucault procurou reabilitar esta importante dimensão da parrhesía, a do "dizer verdadeiro como uma arte da existência utilizada pelo sujeito na sua autotransformação".

Como observamos e vale ressaltar, o risco é implícito e inerente à parrhesía. O parresiasta, como aponta Foucault (2011, p.24), “assume um risco. Ele arrisca a relação que tem com aquele a quem se dirige", podendo, inclusive, suscitar "a possibilidade do ódio e da dilaceração", pois a parrhesía é, conforme a aula inicial do último curso do filósofo francês8, "a coragem da verdade naquele que fala e assume o risco de dizer, a despeito de tudo, toda a verdade que pensa" (FOUCAULT, 2011, p.13) ou ainda "dizer tudo, mas indexado à verdade: dizer tudo da verdade, não ocultar nada da verdade, dizer a verdade sem mascará-la com o que quer que seja" (FOUCAULT, 2011. p.11).

O autor ainda ressalta que a memória desempenha um papel crucial, mas ele aponta também outros pontos na ascese da verdade: 1) a escuta, de suma relevância para tanto estoicos quanto epicuristas, para os quais se deve primeiro calar e escutar; 2) a escrita pessoal (hupomnèmata, caderno sobre temas importantes) que inclui "tomar notas das leituras, das conversas, das reflexões que se ouvem ou se fazem a si mesmo" (FOUCAULT, 1997, p.129), notas que devem ser lidas e relidas constantemente; 3) voltar-se para si ou anachorèsis eis heauton como utilizada por Marco Aurélio, no sentido de exercícios de memorização do que se aprendeu.

Para elucidar e aprofundar a noção de cuidado de si da Grécia Antiga, retomada por Foucault, optamos por recorrer a uma das fontes consultadas por Foucault em seus estudos, Hadot, especificamente, seu livro Exercícios espirituais e filosofia antiga. Hadot fala-nos de uma visão estética, um meio para reaprender a ver e a ser no mundo e do ato filosófico como uma conversão, conversão de si mesmo, conversão esta que "subverte toda a vida, que muda o ser daquele que a realiza" (HADOT, 2014, p.22), ou em termos plotinianos, "esculpir sua própria estátua".

De acordo com o autor, há uma enorme variedade e riqueza de exercícios espirituais

\footnotetext{
${ }^{8}$ Foucault inicia seu último curso, A coragem da verdade: o governo de si e dos outros II, em 10 de fevereiro de 1984, explicando: "Não pude começar meu curso, como de costume, no início de janeiro. Estive doente, doente mesmo. Correram boatos de que era para me livrar de uma parte do meu público que eu havia trocado as aulas. Não, não, eu estava doente mesmo. [...]. O autor lecionou até 28 de março de 1984, vindo a falecer 3 (três) meses depois, em 25 de junho do mesmo ano, aos 57 anos.
}

Periódico Horizontes - USF - Itatiba, SP - Brasil - e019028 
(práticas de si) na Antiguidade. Cada escola filosófica possuía seus exercícios, havendo variações tanto em sua tonalidade afetiva e em seu conteúdo nocional. Para os estoicos, por exemplo, envolvia a mobilização da energia e o consentimento ao destino. Já no epicurismo, seu foco era a descontração e o desapego. Para os platônicos, implicava concentração mental e renúncia ao sensível. Porém, segundo Hadot (2014), a figura de Sócrates, que foi e continua sendo um apelo vivo à consciência moral, é a responsável pela imersão desse conceito na consciência ocidental.

Hadot (2014) define exercício espiritual como uma prática destinada a realizar uma mudança radical do/no ser. São mais do que exercícios proposicionais e/ou conceituais, mas sim uma prática, um trabalho sobre si mesmo que devem ser vivenciados, experimentados. Tais exercícios, em vez de informar, visavam a formar. Não se trata de uma construção teórica simplesmente, mas de uma experiência, um exercício de formação de si, da Paidea ${ }^{9}$. Conforme Hadot (2014), podemos ter uma ideia da amplitude desse tipo de exercício graças às listas de exercícios espirituais estoicos que nos foram legadas por Filo de Alexandria.

Uma dessas listas enumera: pesquisa (zetesis), o exame aprofundado (skepsis), a leitura, a audição (akroasis), a atenção (prosochè), o domínio de si (enkrateia), a indiferença às coisas indiferentes. A outra nomeia sucessivamente: as leituras, as meditações (meletai), as terapias das paixões, as lembranças do que é bom, o domínio de si (enkrateia), a realização dos deveres (HADOT, 2014, p.25).

A prosochè, atenção ao momento presente, é essencial tanto para os estoicos quanto para os epicuristas. Trata-se de uma "vigilância e uma presença de espírito contínuas, uma consciência de si sempre desperta, uma tensão constante do espírito" (HADOT, 2014, p.25) para distinguir aquilo que depende de nós e aquilo que não depende. Hadot (2014) ressalta que a atenção ao momento presente é, de certo modo, o segredo dos exercícios espirituais, pois nos "liberta da paixão que o passado ou futuro, que não dependem de nós, sempre provocam; ela facilita a vigilância, concentrando-se sobre o minúsculo momento presente, sempre dominável, sempre suportável, em sua exiguidade" (HADOT, 2014, p.26). Ainda, segundo o autor, a atenção permite-nos responder prontamente aos acontecimentos ainda que nos acerquem de forma

\footnotetext{
${ }^{9}$ Termo grego, surgido na época homérica, referente ao sistema de educação e formação ética da Grécia Antiga, que incluía temas variados, dentre eles a Filosofia, visando à formação de um cidadão perfeito e completo, capaz de liderar e ser liderado e também desempenhar um papel positivo na sociedade.
}

Periódico Horizontes - USF - Itatiba, SP - Brasil - e019028 
repentina, mas para tal, faz-se necessário ter sempre os princípios fundamentais da escola filosófica à qual se pertence procheiron (sempre à mão). Vale destacar que, embora envolva o pensamento, os exercícios envolvem também a imaginação e a afetividade, todos em prol da transformação da personalidade.

Sobre a meditação, diferentemente do conceito ocidental, esta envolve memorização (mnemè) e a própria meditação (meletè) da regra de vida por meio de leitura, audição, pesquisa, exame aprofundado e também por meio da escrita. Ao meditar, o indivíduo "se esforça para dominar o discurso interior, para torná-lo coerente, para ordená-lo a partir do princípio simples e universal que é a distinção entre o que depende de nós e o que não depende de nós, entre a liberdade e a natureza" (HADOT, 2014, p.29). Um exemplo é a meditação constante do tetrapharmakon (quádruplo remédio) dos estoicos: "os deuses não são temíveis, a morte não oferece risco, o bem é fácil de adquirir, o mal é fácil de suportar" (HADOT, 2014, p.33). Acreditava-se que a meditação dos dogmas fundamentais da escola podia levar à cura da alma.

Ainda sobre os exercícios espirituais, Hadot (2014) salienta que, além de estarem relacionados a aprender a viver, envolvem aprender a dialogar, aprender a morrer e aprender a ler, sendo escrever, reescrever, ler e reler movimentos de construção de si, do mundo e dos outros.

Como em todo exercício espiritual, no diálogo, quer seja socrático ou platônico, "é preciso fazer a si mesmo mudar de ponto de vista, de atitude, de convicção; portanto, dialogar consigo mesmo; portanto, lutar consigo mesmo" (HADOT, 2014, p.41). Ademais, "todo exercício espiritual é dialógico na medida em que é exercício de presença autêntica perante si e perante os outros" (HADOT, 2014, p.40).

Aprender a morrer ou exercitar-se para a morte, um outro tipo de exercício espiritual, exige uma concentração do pensamento sobre si mesmo, um esforço de meditação, um diálogo interior, significa preparar-se para "a morte de sua individualidade, de suas paixões, para ver as coisas na perspectiva da universalidade e da objetividade" (HADOT, 2014, p.45). Graças a este exercício, é possível manter a serenidade na infelicidade, por meio dele, saímos da subjetividade individual e passional para a objetividade universal. Para os estoicos, além da possibilidade de encontrar a liberdade por meio do exercício da morte, tal exercício envolve também aprender a

Periódico Horizontes - USF - Itatiba, SP - Brasil - e019028 
contemplar. Segundo Filo de Alexandria (apud HADOT, 2014, p.50), os que praticam a sabedoria sabem contemplar a natureza de forma especial.

Para o epicurista, para o qual um dos lemas cardinais é carpe diem, o exercício da morte está relacionado à "consciência da finitude da existência e ela dá um valor infinito para cada instante; cada momento da vida surge carregado de um valor incomensurável" (HADOT, 2014, p.46-47), o que envolvia viver o dia, o instante como se fosse primeiro e, ao mesmo tempo, o último, como se a vida fosse acabar naquele instante.

Em suma, apesar da diferença e da diversidade, Hadot (2014) salienta que há uma unidade, tanto nos meios quanto na finalidade, entre tais exercícios. Usam-se como meios as técnicas retóricas e dialéticas de persuasão, as tentativas de domínio da linguagem interior, a concentração mental. Quanto à finalidade, em todas as escolas, esta está relacionada ao aperfeiçoamento e à realização de si. Todas as escolas acreditam que a conversão filosófica é essencial ao homem para que este possa libertar-se de seu estado de inquietude e infelicidade, dos grilhões das preocupações e paixões, para aperfeiçoar-se, transformar-se, alcançar a perfeição. Dito de outro modo,

todo exercício espiritual, portanto, é fundamentalmente um retorno a si mesmo, que liberta o eu da alienação na qual as preocupações, as paixões, os desejos o haviam enredado. $\mathrm{O}$ eu assim liberto não é mais nossa individualidade egoísta e passional, é nossa personalidade moral, aberta à universalidade e à objetividade, participando da natureza e do pensamento universais (HADOT, 2014, p.57)

Cabe também mencionar que os exercícios espirituais, intrinsecamente relacionados à filosofia (amor pela sabedoria), deverão sempre ser retomados num esforço sempre renovado, conversão esta que deve ser (re)conquistada incessantemente, ao longo de toda a existência. Na medida em que a vida filosófica é sinônimo de prática desses exercícios, ela é "um desenraizamento da vida cotidiana: ela é uma conversão, uma mudança total de visão, de estilo de vida, de comportamento" (HADOT, 2014, p.58). Implicava uma inversão radical dos valores recebidos, na qual, "renunciava-se aos falsos valores, às riquezas, às honras, aos prazeres para se voltar para os verdadeiros valores, a virtude, a contemplação, a simplicidade da vida, a simples felicidade de existir" (HADOT, 2014, p.58).

Periódico Horizontes - USF - Itatiba, SP - Brasil - e019028 


\section{Análise discursiva}

O levantamento do corpus contou com a gravação e transcrição das entrevistas semiestruturadas de seis (seis) sujeitos-professores-participantes, com idade entre 30 e 65 anos, professores em duas instituições de ensino superior do Vale do Paraíba Paulista, uma privada e outra pública. As entrevistas foram gravadas entre 28.11.2015 a 05.08.2016, nas dependências das próprias instituições em que lecionavam os sujeitos-professores-participantes e a pesquisadora, em horários pré-acordados. Cabe mencionar que a pesquisa da qual provém este artigo está vinculada à linha de Pesquisa "Educação, Linguagens e Processos interativos" do Programa de Pós-graduação em Educação da Universidade São Francisco e que foi autorizado por seu Comitê de Ética em Pesquisa em 12.11.2015, sob o parecer número 1.322.

Neste artigo, excertos de entrevistas realizadas com quatro dos participantes são analisados à luz da Análise do Discurso de linha francesa, na perspectiva peucheutiana e foucaultiana, e em seus entrelaçamentos com a Psicanálise.

Empreender uma análise na/pela perspectiva discursiva requer fazer aparecer os aspectos referentes à forma de existência social dos sujeitos tendo em vista os aspectos linguísticos, sociais e históricos que engendram sua constituição nas formações discursivas, na formação e transformação desses sujeitos e dos objetos que constituem (FERNANDES, 2012, p.30).

A análise do discurso "busca descrever e interpretar a constituição, a formulação e a circulação dos sentidos na sociedade, mediante a articulação necessária e indissociável da língua com a história" (PIOVEZANI; SARGENTINI, 2017, p.15). Tendo isso em mente, buscaremos rastrear possíveis presenças do cuidado de si filosófico, com base em Foucault e Hadot, modos singulares pelos quais os sujeitos-professores-participantes tentam afrouxar as amarras das técnicas neoliberalistas de governamentalidade com o objetivo de fazer-se diferente ou, em termos foucaultianos, esculpir-se como uma obra de arte, num eterno vir a ser, um eterno ensaio de si.

Comecemos pela visão geral de Luana ${ }^{10}$ sobre a profissão docente e o cuidado (de si).

\footnotetext{
10 Tratam-se de pseudônimos escolhidos aleatoriamente para este artigo, não os nomes reais dos sujeitosprofessores-participantes.
}

Periódico Horizontes - USF - Itatiba, SP - Brasil - e019028 
Ah::: eu acho que a maioria tem pensado muito em realmente trabalhar, trabalhar, trabalhar, trabalhar, trabalhar mas no ensino... até o Ensino Médio... né... é::: que é onde a gente ganha menos... né... tem você tem que dar MUITAS AULAS pra ter um salário razoável... então você é OBRIGADO a trabalhar bastante... então sobra pouco tempo realmente pra pessoa se cuidar... mas na... já no ensino superior... e acho que as pessoas têm... se preocupam... os professores de ens... os professores se preocupam um pouco MAIS porque a gente tem um rendimento um pouco MELHOR então né você CONSEGUE abrir mão de algumas coisas e ainda ter um salário UM POUQUINHO melhor pra poder cuidar de si, como eu... por exemplo... né...

Notamos que o discurso neoliberalista/capitalista é materializado de diversas formas no excerto acima, a começar pela repetição em sequência do verbo "trabalhar" antecedido pelo advérbio de intensidade "realmente"; pela forma enfática "muitas aulas" e em especial pelo uso de "ser obrigado", com destaque ao "obrigado", seguido de "trabalhar" e o advérbio de intensidade "bastante". Ademais, também está presente no trecho "ter um salário razoável".

Com respeito ao professor de ensino superior, Luana acredita que devido ao fato de terem "um rendimento um pouco melhor", consegue "abrir mão de algumas coisas", "coisas" aqui por nós interpretadas como aulas, sem prejuízo financeiro, o que notamos em "e ainda ter um salário UM POUQUINHO melhor", podendo, por esse motivo cuidar(-se). O cuidado (de si) aparece aqui reservado aos mais afortunados em termos econômicos, ou seja, o efeito de sentido levantado é o de que "sem dinheiro, não há cuidado (de si)".

O uso do pronome pessoal do caso reto em primeira pessoa "eu" no final do excerto, a título de exemplificação, salienta que Luana pôde deixar algumas tarefas de coordenação e administração e também aulas na IES, na qual leciona há aproximadamente uma década, em especial em 2016, após eventos médicos para cuidar melhor (de si). A professora passou a (re)pensar sua rotina, seu trabalho, sua vida, de forma que o cuidado (de si) passasse a integrar seu dia a dia, afinal, como ela afirma, em outro momento da entrevista, "não desejava morrer". O agente mobilizador do cuidado (de si), como aponta a fala de Luana, foi o medo da morte precoce. Este dizer parece remeter-nos ao exercício espiritual "aprender a morrer ou exercitarse para a morte", através do qual, segundo Hadot (2014), passamos, por meio da consciência da finitude de nossa existência terrena, a valorizar cada instante de nossa vida.

Vale neste ponto mencionar que, no final de 2014, Luana teve um AVC, ficando na UTI 
por quase um mês. No final de 2015/começo de 2016, foi novamente hospitalizada, tendo, em 2016, descoberto uma doença autoimune e realizado vários tratamentos, inclusive quimioterapia. Segundo Luana, em áudio enviado por Whatsapp em 09.09.2017, foi diagnosticada com "arterite de takayasu", doença autoimune de fundo psicológico. Alegou que durante o mestrado (2006-2008) teve problemas endocrinológicos, tendo desenvolvido hipertireoidismo, passando, desde então, a ter baixa imunidade. Na sequência, teve toxicoplasmose e, por último, desenvolveu uma inflamação nas artérias. Por estresse provocado não só pelo acúmulo de trabalho, em um mês em que era membro da comissão de organização do evento de iniciação científica anual da IES na qual leciona, mas também por problemas familiares e por uma situação ocorrida no centro espírita que frequenta, um coágulo desprendeu-se na carótida, entupindo um vaso cerebral, ocasionando AVC isquêmico e outro hemorrágico. Tal evento deixou cicatrizes no cérebro de Luana que levaram a convulsões em 2016, conforme depoimento concedido.

No áudio mencionado acima, enviado à pesquisadora em resposta à solicitação de autorização para mencionar todo o ocorrido na tese e publicações decorrentes, a entrevistada, além de detalhar seu quadro clínico, relatou que ele foi desencadeado por estresse, por esgotamento físico, por falta de relaxamento, não só por problemas no trabalho, mas também por doenças na família, pela construção de sua casa, entre outros. Luana atribui parte de seus problemas a como ela "encara as coisas", às crenças passadas pelos pais. Disse que, após o ocorrido, com o auxílio da terapia, do Yoga e do tratamento medicamentoso, "pôs o pé no freio", "mudou de ponto de vista", passou a "valorizar outras coisas" e tem "consciência de que o que importa é como encara tudo". Cabe aqui citar a posição birminiana (2009) de que o desamparo e o mal-estar são inerentes em nossas vidas e que a questão fundamental é aprender a gerenciálos para poder (con/sobre)viver nos terrenos inóspitos, com curvas inesperadas e subidas íngremes da contemporaneidade. Retomando a metáfora geográfica, quando os mapas já não dão mais conta do terreno, cabe-nos usar um GPS, recalculando nossa rota diuturnamente, porém, sem uma rota (pré)definida desde o princípio, abertos aos imprevistos e às possibilidades de transformação. Observa-se aqui também o desejo de fazer e de ser diferente, de transformarse em decorrência do ocorrido, ou seja, o recorte discursivo acima também aponta para 
vislumbres do cuidado de si foucaultiano.

Já na primeira entrevista, quando interrogada sobre o que era cuidado (de si), Luana contestou:

Bom... HOJE... depois de umas experiências que eu tive... cuidar de mi:: de si no meu caso de mim eh:: fazer tudo que me agrada neh que são compromissos responsabilidades mas de uma maneira PRAZEROSA pra mim... então por exemplo trabalhar... TRABALHAR é uma coisa que eu tenho que fazer todo mundo tem que fazer mas que seja então um trabalho por prazer... não só um trabalho por obrigação...

O deslizamento entre o cuidar "de mi::" para "de si", não pronunciado na íntegra e com pausa para reformulação, parece remeter-nos levemente ao processo de conversão foucaultiana em andamento, pois para o autor o cuidado de si implica uma conversão do exterior para o interior, ou seja, após "umas experiências que eu tive", que aqui se referem aos problemas de saúde apresentados acima, a professora parece ter iniciado o processo de olhar mais para seu interior, buscando maneiras de transformar a maneira como encara seu trabalho ou ainda se encara frente ao trabalho, pois nas palavras de Foucault (2010, p.12) "cuidar de si mesmo implica que se converta o olhar[...] do exterior, dos outros, do mundo etc. para 'si mesmo'".

Já Gabriel, quando perguntado sobre "o que é cuidado (de si) para você?”, contestou:

Eu vejo CUIDAR DE MIM... seria eu... cuidar de si... né... seria... eu percebo como eu olhar... eu conseguir sair do meu corpo e observar... EU... como pessoa... como Gabriel... na minha família... no meu ambiente de trabalho... é:: na... as minhas relações com as pessoas... né... na minha própria saúde FísICA... conseguir PERCEBER o... a minha parte mental... o meu emocional como é que tá... como é que eu estou come.... tomando cuidado disso tudo... né... isso eu percebo...CLARAMENTE... afeta e tem consequências no ambiente dele.

Chama-nos a atenção o uso do verbo perceber, não só neste trecho, mas também ao longo de toda a entrevista gravada, aqui usado três vezes e, na última, associado ao advérbio de modo "claramente". O entrevistado é espírita, fato observado não só pela frase "eu conseguir sair do meu corpo e observar", mas por menção em trecho posterior da entrevista, o que o leva possivelmente a associar o cuidado (de si) ao conceito de reforma íntima, caro a esta doutrina e 
pelo qual o praticante deve, dentre outros, emudecer a agressividade; treinar a paciência constantemente e ouvir fraternalmente ${ }^{11}$, prática esta a ser evidenciada nos excertos abaixo.

No trecho acima é como se o entrevistado saísse de si e se olhasse como se fosse outro para si próprio e para sua relação com os outros e o entorno, em especial pelos pronomes em terceira pessoa usados no início e no final do excerto "cuidar de si" "no ambiente dele". Este efeito de sentido remete-nos ao conceito de consciência cósmica de Hadot (2014), segundo o qual devemos buscar ter a consciência de viver no cosmos e com ele nos harmonizarmos, o que, segundo o autor, acontece por meio da "experiência vivida do sujeito concreto, vivente e percipiente" (HADOT, 2014, p.272).

Gabriel parece esforçar-se para atentar-se para vários aspectos de sua vida, como notamos em sua fala "como pessoa... como Gabriel... na minha família... no meu ambiente de trabalho... é:: na... as minhas relações com as pessoas... né... na minha própria saúde FísICA ... conseguir PERCEBER o... a minha parte mental... o meu emocional como é que tá... como é que eu estou come... tomando cuidado de tudo isso", e especialmente no emprego do pronome indefinido "tudo", o que nos remete à ideia de completude, de responsabilização do sujeito por sua vida e pelas consequências de seus atos e omissões, como explicita Gabriel em "afeta e tem consequências".

Se por um lado a estratégia de Gabriel, via reforma íntima, de olhar-se com distância para perceber "CLARAMENTE" quem é, o que e como tem feito, aproxima-se do trabalho de esculpirse apontado por Foucault e Hadot, por outro, se acerca também das técnicas neoliberais de governamentalidade, que visam conduzir condutas de modo indireto, usando o próprio sujeito como agente do cuidado (de si).

Dando continuidade à resposta, Gabriel diz:

... no ambiente de trabalho... eu procuro mais OUVIR do que falar... porque eu procuro falar quando é necessário... me colocar quando é necessário... e:: procuro... fazer aquilo que eu sei que é certo com muita... muita CERTEZA MESMO... se eu tiver alguma dúvida... eu não vou fazer... agora nesse momento

\footnotetext{
${ }^{11}$ FONTE: http://www.mensagemespirita.com.br/chico-xavier/ad/20-exercicios-para-reforma-intima. Acesso em: maio 2017.
} 
de transição que a gente tá vivendo $A Q U I$ né $^{12}$... é::: eu percebi muito isso... dessa ideia de ouvir e tentar levar pra sala de aula Só o MELHOR... então eu ouço muito... me coloco às vezes... e cuido muito dessas relações interpessoais aí porque... você tem um... é um jeito que a gente tem aí de manter o ambiente sadio...

No trecho acima, observa-se a aproximação com o conceito de espiritualidade política (BALL, 2016), ou com a vontade de descobrir uma nova forma de governar a si próprio, em especial pela presença das palavras "certo" e "certeza", esta associada ao advérbio "mesmo" dito de forma enfática e pelo enunciado "procuro fazer o que sei que é certo". Os vocábulos "certo" e "certeza" podem também apontar para a importância dada por Gabriel a agir de forma ética, de acordo com seus princípios. Há também a repetição do vocábulo "ouvir" associado às palavras como "melhor" e "muito" que, de acordo com Gabriel, deve ser priorizado, juntamente com o observar, em detrimento do falar. Tal posicionamento é necessário, pelos dizeres de Gabriel, em especial, no "momento de transição" que estavam, ele e a entrevistadora, vivendo na instituição privada na qual lecionavam e para manter o "ambiente sadio", sadio, vocábulo ligado à área médica, que nos remete novamente a uma certa preocupação também com o "cosmos", aproximando, como dissemos acima, do conceito de consciência cósmica de Hadot (2014).

Retomamos aqui também que "audição, pesquisa e exame aprofundado", que faziam parte dos exercícios espirituais na Antiguidade Grega, como apontado por Foucault e Hadot, são materializados nos dizeres de Gabriel acima. Foucault (1997) salienta que a escuta era de suma relevância tanto para os estoicos quanto os epicuristas, para os quais era necessário primeiro calar e escutar, postura esta adotada por Gabriel, conforme observamos na materialidade linguística.

Ainda a respeito de como se cuida, Gabriel aborda a questão da espiritualidade:

... eu sou ESPÍRITA... então eu frequento o centro espírita... eu... eu faço tratamento espiritual... eu faço um curso à distância... né... de:: de:: de... chama "aprendiz do evangelho"... então... eu tô sempre lendo... sempre estudando... percebendo muita coisa... que a gente tá vivendo hoje... né... casa muito com

\footnotetext{
${ }^{12}$ No momento da entrevista, a instituição na qual trabalhavam tanto o entrevistado quanto a entrevistadora estava passando pelo processo de adoção de metodologias ativas de aprendizagem e de alocação de disciplina ou parte da carga horária de algumas disciplinas para o sistema EAD.
}

Periódico Horizontes - USF - Itatiba, SP - Brasil - e019028 
aquilo que eu acredito... e eu sei que tá tudo no caminho certo... eu aprendi a não RECLAMAR... aprendi a fazer as coisas da melhor maneira POSSíVEL... aprendi a não DUVIDAR DE MIM... aprendi também é que não um... um jeito fácil de fazer a coisa... mas também não existem coisas impossíveis de se fazerem... você também... como professora deve saber... hoje do jeito que a gente tá PRECISANDO MUDAR e a primeira coisa que a gente ouve é que isso não dá certo... a primeira coisa que a gente ouve... então eu aprendi que não existe isso... então essa ligação aí entre... essa relação que eu tenho com a parte espiritual... ela vem se fortalecendo MUITO... e eu percebo que a gente tem que estar BLINDADO MESMO... porque o nosso entorno... ele é muito negativo... né...

Gabriel parece encontrar brechas via espiritualidade para pensar a si mesmo e a sua prática docente de forma diferente, em meio ao turbilhão de incertezas, inconstâncias e malestares do momento contemporâneo, pois, conforme ele, "nosso entorno... ele é muito negativo". Usando as próprias palavras de Gabriel, ele busca constantemente formas de "ESTAR BLINDADO MESMO". Vejamos que o termo "blindar" está inicialmente relacionado à guerra, à construção de proteção utilizada em veículos para proteção pessoal contra armas de fogo. "Blindar" é uma metáfora de guerra, de ver a vida como uma guerra e para se cuidar, é preciso "estar blindado".

Parece-nos que para Gabriel, como aponta Ball (2016), a luta começa pela relação consigo mesmo, no pensar(-se) diferente. Trata-se da forma socrática de autoexame, uma atividade de (re)fazer artesanalmente a relação consigo mesmo e com os outros dentro das restrições que nos são impostas, um trabalho crítico que envolve desestabilizar formas habituais de fazer e ser e também positivo, abrindo espaços nos quais é possível ser diferente. Tal efeito de sentido materializa, em especial, em "aprendi a não RECLAMAR... aprendi a fazer as coisas da melhor maneira POSSÍVEL... aprendi a NÃO DUVIDAR DE MIM... aprendi também é que não (há) um... um jeito fácil de fazer a coisa...", com atenção ao verbo conjugado na primeira pessoa do singular no pretérito perfeito, que nos aponta para o fato de que tais comportamentos/ ações/pensamentos não eram comuns a/em Gabriel no passado. A este respeito, Ball (2016) ainda salienta que não se trata de meramente negar ou resistir à verdade, ao poder, à riqueza, mas sim tentar articulá-los e/ou dispor deles de outra forma, ou seja, o processo de autotransformação exige engajamento na busca pela formação de uma arte de viver e de ensinar. 
Vale aqui retomar o alerta que faz Ball (2016) sobre o risco da espiritualidade política e também nos lembrarmos do risco do ato parreriástico. Gabriel, por discordar de certas imposições e mudanças no que tange à docência, em especial ao regime de atribuição de aulas, feitas pela instituição na qual trabalhava durante a entrevista, embora considerado um ótimo professor pelos alunos e coordenadores, acabou saindo, um tempo depois de realizada esta entrevista, de forma não muito amigável, da instituição/empresa.

No que tange ao cuidado (de si) como espiritualidade, Clara disse:

Essa é a parte que AINDA (RSSS DE AMBAS) eu tenho que melhorar... o espiritual eu cuido sozinha, mas eu quero ter um LUGAR para IR... quero ter um GRUPO... uma troca de experiência... isso que eu tô procurando encontrar AINDA... mas eu tenho o MEU momento comigo mesma e com Deus maior agora também...

No excerto, Clara confessa, nos moldes foucaultianos, não trabalhar muito este aspecto. Para Foucault (1997), a confissão é um mecanismo positivo, produtor de saber, multiplicador de discursos e gerador de poder. Trata-se de um ritual do discurso, no qual

o sujeito que fala coincide com o sujeito do enunciado; é também, um ritual que se desenrola numa relação de poder, pois não se confessa sem a presença ao menos que virtual de um parceiro, que não é simplesmente o interlocutor, mas a instância que requer a confissão, impõe-na, avalia-a e intervém para julgar, punir, perdoar, consolar, reconciliar; um ritual onde a verdade é autenticada pelos obstáculos e as resistências que teve de suprimir para poder manifestarse; enfim, um ritual onde a enunciação em si, independentemente de suas consequências externas, produz em quem a articula modificações intrínsecas: inocenta-o, resgata-o, purifica-o, livra-o de suas faltas, libera-o, promete-lhe a salvação (FOUCAULT, 1997, p.61).

Ainda sobre este mecanismo colocado em marcha pela entrevista, parece-nos que, de certo modo, para alguns dos sujeitos, como para Clara, a entrevista incita o sujeito-professorparticipante a desejar o cuidado (de si), foco da tese da qual deriva este artigo.

Cabe também apontar para o uso do advérbio de intensidade "AINDA" dito com destaque e seguido de risos, tanto de Clara quanto da pesquisadora, como materialização da formação imaginária de que a pesquisadora é uma pessoa que busca cuidar (de si), neste caso, no que tange à espiritualidade. Afinal, o falar de si, semelhantemente à escrita de si para Foucault (1997,

Periódico Horizontes - USF - Itatiba, SP - Brasil - e019028 
p.52), nunca é apenas falar de si, uma vez que "a constituição de si se dá a partir da recolha do discurso dos outros". A este respeito, Eckert-Hoff (2008, p.41), com base em Foucault, salienta que ao falar de si, de sua história, de sua vida, o sujeito "jamais se descreve, tal que ele 'seria', tal qual ele deseja se mostrar. Das palavras ditas, irrompem sentidos fluidos, escorregadios, imprevisíveis, incontroláveis".

No momento final da entrevista, momento de choro de Clara, ela também mencionou que já havia feito terapia, que, antes, pensava que terapia era "para gente que não tem amigos". Disse que, na primeira tentativa, não se adaptou à linha, mas que havia achado outro psicólogo que havia acertado e, hoje, mesmo tendo alta dele, uma vez por mês agenda uma consulta. Interessantemente, a gravação gerou uma proximidade que a pesquisadora e a participante não tinham antes. E a conversa informal, após o encerramento da gravação, após Clara acalmar-se, não registrada pela sensibilização provocada, também evidencia o efeito de confissão que operou a entrevista em Clara, mas também na própria entrevistadora. Evoca também o fato de que, como muitos docentes, Clara, parece ter indícios de um esgotamento emocional e físico, notado não só pelo choro no meio da entrevista, mas também porque a professora apresentou problemas de saúde no 20 semestre de 2016, tais como pressão alta, dor na nuca, tontura e desmaio, inicialmente diagnosticados como estresse, o que foi relatado pela entrevistada à pesquisadora em momento posterior às entrevistas.

Vale trazermos aqui o alerta feito por Birman (1999) de que, na contemporaneidade, há muitos professores que sofrem de/com doenças psicossomáticas, panicados e deprimidos nas palavras do autor, cujo mal-estar pode ser intensificado devido à consideração do outro em detrimento de si, em especial em uma sociedade que ainda vê a docência como missão, sacerdócio, que espera e cobra excelentes resultados, altos índices e que demanda por sujeitos autocentrados que se cuidem.

Aurea, evangélica, também demonstra seu desejo por cuidar (de si), mas aponta a falta de tempo como um empecilho para suas atividades espirituais, como notamos em "[...] ... não encontro tempo [...] até mesmo é::: uma coisa que eu acho interessante...é::: até mes... pra mim é muito importante...tá... a vida espiritual... até ISSO afeta...porque às vezes eu me vejo tão assim....".

Periódico Horizontes - USF - Itatiba, SP - Brasil - e019028 
Vale mencionar que a gravação foi interrompida neste ponto por problemas técnicos e que, durante o tempo aproximadamente 5 minutos, nos quais a pesquisadora tentava resolver o impedimento técnico, houve um diálogo com a entrevistada, no qual ela disse que se sente mal quando passa um dia sem ler a Bíblia, sem orar. Alegou que embora orar e ler a Bíblia lhe façam muito bem, não sabe por que não o faz às vezes. Aurea também relatou ser detalhista e que ter sido diagnosticada por uma psicóloga como portadora da "síndrome de simetria", alegando que a Enfermagem acentuou sua mania de querer tudo perfeito. Disse que adotar duas cadelas ajudou-a na superação deste aspecto, pois com elas "nem tudo está a todo momento $100 \%$ organizado". Mencionou ainda que parou a terapia por conta própria, mas não entrou em detalhes a respeito.

\section{Ensaio final}

Conseguir suportar ou gerir a dor provocada pelo desamparo é o grande desafio da atualidade. "Isso porque as subjetividades demandam ainda uma cura para o desamparo e o malestar. A ilusão continua lá, intacta, nos corações e mentes dos indivíduos" (BIRMAN, 1999, p.144). Esse desamparo produzido pela Modernidade teve como uma de suas consequências devastadoras a produção de individualidades homogeneizadas que conduz, de acordo com Birman (1999), ao individualismo, a uma sensação de desamparo nunca antes vivenciada e até ao masoquismo devastador. Nessa posição de desamparo, o sujeito "pode construir efetivas possibilidades de sublimação e de criação, pela construção de uma forma singular de existência e de um estilo próprio para habitar seu ser" (BIRMAN, 1999, p.45), acreditando que "da fronteira com o horror do impossível, o sujeito vai advir" (BIRMAN, 1999, p.46). Porém, a característica principal da sociedade de massa na qual vivemos "é justamente a homogeneidade das individualidades, pois estas não apresentam nem certa singularidade em seu ser nem um estilo próprio de existência" (BIRMAN, 1999, p.47-48). Para Freud, a via de escape de tal desamparo era a sublimação, que segundo o psicanalista brasileiro é "a produção de algo que seja da ordem do sublime, no que isso significa de ruptura com a homogeneidade, em oposição ao belo" (BIRMAN, 1999, p.49). Por meio dela, "a força pulsional se encaminharia para a busca de novas 
ligações e de novos objetos de investimento" (BIRMAN, 1999, p.63).

Ademais, houve uma transformação gigantesca da ordem do sujeito e do desejo na passagem da sociedade moderna à pós-moderna. Com isso, o sujeito "não consegue mais acreditar, como anteriormente, que pode transformar a si mesmo e ao mundo com seu desejo, de maneira a poder reinventar a si mesmo e a ordem social" (BIRMAN, 1999, p.82). Dito de outro modo, a crença no desejo como condição de reinvenção de si mesmo foi uma das perdas provocadas pela Pós-Modernidade. "Assim, as culturas do narcisismo e do espetáculo construíram um modelo de subjetividade em que se silenciam as possibilidades de reinvenção do sujeito e do mundo" (BIRMAN, 1999, p.85).

A este respeito, Ortega (1999, p,23), em consonância com Ball (2016) fala da necessidade de uma política espiritual, ou seja,

\begin{abstract}
da elaboração de uma relação não normatizada (nem normatizável) consigo como alternativa às estratégias de subjetivação do poder disciplinar moderno e do biopoder - subjetividade como decisão ético-estética, como cuidado de si, e não como objeto de um poder "des-cuidante". 0 indivíduo possui a capacidade de efetuar determinadas operações sobre si para se transformar e constituir para si uma forma desejada de existência (Foucault denomina este processo ascese ou tecnologias de si). [...] A relação consigo oferece uma alternativa a Foucault, uma forma de resistência diante do poder moderno. A ascese representa uma arma, uma possibilidade de "se equipar". A política, entendida nestes termos, é uma política espiritual, uma revolução da alma.
\end{abstract}

Em suma, Ortega salienta que o cuidado de si é concebido por Foucault como "o ponto de resistência preferencial e útil contra o poder político, e localiza o objetivo político no fomento de novas formas e subjetividade" (ORTEGA, 1999, p.153). Ainda segundo Ortega (1999), Foucault defende "a criação de novos esboços de si mesmo que não tenham obrigatoriamente como resultado a formação de um sujeito dócil" (ORTEGA, 1999, p.154).

Como pudemos observar, para Foucault $(2010 ; 2013)$ e para Hadot, a Filosofia como modo de vida está relacionada à tranquilidade da alma (ataraxia), à liberdade interior (autarkeia), ao desapego (aprospatheia), à ausência de paixões (apatheia) etc., conduzindo o homem à consciência cósmica, isto é "a consciência de fazer parte do cosmos, a dilatação do eu na infinitude da natureza universal" (HADOT, 2014, p.264). Tratava-se, na antiguidade, do 
“resultado de um exercício espiritual que consistia em tomar consciência do lugar da existência individual na grande corrente do cosmos, na perspectiva do Todo" (HADOT, 2014, p.272). O autor também ressalta que a consciência cósmica não estava relacionada ao conhecimento científico, objetivo e matemático do Universo, mas este exercício situava-se na "experiência vivida do sujeito concreto, vivente e percipiente" (HADOT, 2014, p.272), como menciona Sêneca em Cartas a Lucílio, 66, 6 (apud HADOT, 2014, p.272) "mergulhando na totalidade do mundo" (toti se inserens mundo). Enfim, assim como os sábios antigos, Hadot (2014) recomenda que, a cada instante, tenhamos a consciência de viver no cosmos e de buscar com ele harmonizarmo-nos.

Constatou-se na análise, não sem muita dor, o quão enredados estão os entrevistados, também a pesquisadora e todos, de um modo geral, nas/pelas técnicas neoliberais de governamentalidade, mas também a importância de manter acesa a esperança na possibilidade de fazer de nossas vidas um ensaio de nós mesmos, em constante transformação, apesar de tudo e de todos, pois aquele que pratica concretamente os exercícios espirituais tem a possibilidade de "ver o universo com olhos novos; como se o visse pela primeira vez, ele descobre, no gozo do presente puro, o mistério e o esplendor da existência; e como dizia Nietzsche, nos dizemos então sim "não somente a nós mesmos, mas a toda existência"”" (HADOT, 2014, p.299). Enfim, cada um de nós deve, do seu modo peculiar,

\begin{abstract}
fazer seu voo a cada dia! Pelo menos um momento que pode ser breve, desde que seja intenso. Cada dia 'um exercício espiritual' - sozinho ou acompanhado de um homem que também queira melhorar a si mesmo. Exercícios espirituais. Sair do decurso do tempo. Esforçar-se para despojar-se de tuas próprias paixões, das vaidades, do prurido do ruído em torno do teu nome (que, de tempos em tempos, te prure com um mal crônico). Fugir da maledicência. Despojar-se da piedade e do ódio. Amar todos os homens livres. Eternizar-se ultrapassando-se. Esse esforço sobre si é necessário, essa ambição, justa. Numerosos são aqueles que se absorvem inteiramente na política militante, na preparação da revolução social. Raros, muitos raros aqueles que, para preparar a revolução, querem dela se tornar dignos (FRIEDMAN, 1970, p.359 apud HADOT, 2014, p.19).
\end{abstract}

Em suma, ser sujeito na Pós-Modernidade é "ter de recomeçar insistentemente seu percurso singular, ter de lidar com seu desamparo em um mundo em que universalidade e totalidade não mais existem" (BIRMAN, 1999, p.95). Por isso, estamos todos a todo momento 
buscando, cada um a seu modo, a resposta para a pergunta "o que devo fazer?", esperando desesperadamente por uma fórmula mágica que amenize a dor do desamparo, da angústia, que aplaque as dúvidas e as incertezas e que nos mostre para onde ir de forma segura. Entretanto, há quase um século, foi-nos apontado que tal "pó de pirlimpimpim" inexiste.

A questão seria, então, a de gerir o mal-estar provocado não só pelos -ismos (Neoliberalismo, Capitalismo, entre outros), mas também do gerado por este processo de autotransformação constante, contínuo e necessário, no qual o sujeito nunca é o mesmo, é sempre um incessante vir a ser.

\section{Referências}

AZEREDO, L. A. S. O docente do ensino superior e o cuidado (de si): entre os modos de objetivação e subjetivação na contemporaneidade. 2018. 217p. Tese (Doutorado em Educação) - Universidade São Francisco, Itatiba, 2018.

BALL, S. J. Subjectivity as a site of struggle: refusing neoliberalism? British Journal of Sociology of Education, v.37, n.8, p.1129-1146, 2016.

BAUMAN, Z. O mal-estar da pós-modernidade. Trad. M. Gama e C. M. Gama. Rio de Janeiro: Zahar, 1998.

BIRMAN, J. Mal-estar na atualidade: a psicanálise e as novas formas de subjetivação. Rio de Janeiro: Civilização Brasileira, 1999.

CASTRO, E. El vocabulario de Michel Foucault. Buenos Aires: Prometeo, 2004.

ECKERT-HOFF, B. M. Escrituras de si e identidade: o sujeito professor em formação. Campinas: Mercados das Letras, 2008.

FERNANDES, C. A. Discurso e sujeito em Michel Foucault. São Paulo: Intermeios, 2012.

FOUCAULT, M. Resumo dos cursos do Collège de France (1970-1982). Trad. Andréa Daher. Rio de Janeiro: Zahar, 1997.

FOUCAULT, M. Tecnologias de si. Revista Verve, n.6, p.322-360, 2004. Disponível em: https://revistas.pucsp.br/verve/article/view/5017/3559. Acesso em: fev. 2019.

FOUCAULT, M. Hermenêutica do sujeito. Trad. Márcio Alves da Fonseca e Salma T. Muchail. 3. ed., São Paulo: Martins Fontes, 2010.

Periódico Horizontes - USF - Itatiba, SP - Brasil - e019028 
FOUCAULT, M. A coragem da verdade: o governo de si e dos outros II, curso no Collège de France (1983-1984). Trad. Eduardo Brandão. São Paulo: WMF Martins Fontes, 2011.

FOUCAULT, M. Historia da sexualidade 3: o cuidado de si. Trad. Maria Thereza C. Albuquerque. 12. ed., Rio de Janeiro, Graal, 2013.

FREUD, S. O mal-estar na civilização. Trad. Paulo César de Souza. São Paulo: Penguin Classics Companhia das Letras, 2011.

HADOT, P. Exercícios espirituais e filosofia antiga. Trad. Flavio F. Loque e Loraine Oliveira. São Paulo: É Realizações, 2014.

MORAES, M. C.; NAVAS, J. M. B. Complexidade e transdisciplinaridade em educação. Rio de Janeiro: Wak, 2010.

ORTEGA, F. Amizade e estética da existência em Foucault. Rio de Janeiro: Edições Graal, 1999.

PETERS, M. Governamentalidade neoliberal e educação. In: SILVA, T. S. O sujeito da educação: estudos foucaultianos. 8.ed. Petrópolis: Vozes, 2011, p. 211-223.

PIOVEZANI, C.; SARGENTINI, V. Legados de Michel Pêcheux: inéditos em análise do discurso. São Paulo: Contexto, 2017.

SPARKES, A. C. Embodiment, academics, and the audit culture: a story seeking consideration. Qualitative Research. Los Angeles, v.7, n.4, p.521-550, 2007. DOI:10.1177/1468794107082306.

Recebido em janeiro de 2019.

Aprovado em março de 2019. 